\title{
Comparison of the binding and reactivity of plant and mammalian peroxidases to indole derivatives by computational docking
}

Henrik Hallingbäck ${ }^{\ddagger}$, Razif R. Gabdoulline and Rebecca C. Wade*

Molecular and Cellular Modeling Group, EML Research gGmbH, Schloss-Wolfsbrunnenweg 33, 69118 Heidelberg, Germany.

\section{(1) Heme charge derivation procedures}

The charges for a ferrous heme in CHARMM22 (31) were modified for the ferric, co I and co II states and the charges derived are given in Table S1. Non-polar hydrogens were deleted and their charges were added to the closest non-hydrogen atom according to the united atom principle. The modification to the ferric state was performed simply by adding a +1 e charge to the Fe(III)-ion, resulting in the charge of $+1.24 \mathrm{e}$ on it, which it indeed has been indicated to have (22). Further modifications of the heme charge distribution to represent co I and co II were made according to two schemes designated A and B.

Scheme A was used to derive charges for GRID calculations. It modifies the ferric heme to co I by assigning -0.36e (the charge suggested for carbonyl oxygen by GRID) to the ferryl oxygen and adjusting the $\mathrm{Fe}(\mathrm{IV})$-ion charge to +1.60 e to keep the total charge constant. In the modification from co I to co II, the ferryl oxygen was assigned a charge of -0.13 e (as for hydroxyl oxygen atoms in GRID). The Fe(IV)-ion charge was adjusted accordingly. Almost all the charge (+0.96e) of the added proton of co II was assigned to the Fe(IV)-ion. To keep the total heme charge constant, the charge of all 16 pyrrole carbons were incremented by -0.06e. 
Scheme $B$ was used to derive charges for AutoDock calculations. To enable charge redistribution between the proximal histidine and the heme (27), the heme was considered to be part of the proximal histidine sidechain, thus creating a virtual amino acid type with both the histidine imidazole and the entire heme as a sidechain. Scheme B modifies the ferric heme to co I by assigning -0.36e to the ferryl oxygen. It models the presence of the $\pi$-cation radical by distributing +1.00 e over all 20 carbon atoms of the porphyrin ring. The Fe(IV)-ion charge was adjusted to keep the total charge constant and therefore acquired a charge of $+0.60 \mathrm{e}$. The added proton in co II was represented by adding $+0.60 \mathrm{e}$ to the Fe(IV)-ion. To keep the total heme charge constant, -0.60 e was distributed over the 20 porphyrin carbon atoms. The charge of the ferryl oxygen was left unchanged. This charge distribution scheme is, unlike Scheme A, fairly consistent with the results of density functional theory calculations $(25,27)$.

The charge distribution schemes are empirical, but control calculations with AutoDock using the Scheme A charges displayed very little difference from those using the Scheme B charges. Structural differences seem to have a much larger impact than differences in charge distribution. 
(2) Partial atomic charges assigned to hemes

\section{Table S1}

Heme charges derived from the CHARMM ferrous heme charges according to schemes $A$ and $B$

Charge (e u)

\begin{tabular}{llllll}
\cline { 3 - 4 } Atom no: & $\begin{array}{l}\text { PDB atom } \\
\text { names }\end{array}$ & $\begin{array}{l}\text { IUPAC } \\
\text { atom }\end{array}$ & $\begin{array}{l}\text { Ferric } \\
\text { names }\end{array}$ & state & $\begin{array}{l}\text { co I state: co II state: co I state: co II state: } \\
\text { Scheme A Scheme A Scheme B Scheme B }\end{array}$
\end{tabular}

\begin{tabular}{|c|c|c|c|c|c|c|c|}
\hline 1 & FE & $\mathrm{Fe}$ & 1.24 & 1.60 & 2.33 & 0.60 & 1.20 \\
\hline 2 & $\mathrm{OXO} / \mathrm{OXH} \mathrm{H}^{\mathrm{a}}$ & - & - & -0.36 & -0.13 & -0.36 & -0.36 \\
\hline 3 & $\mathrm{CHA}$ & C15 & 0.00 & 0.00 & 0.00 & 0.05 & 0.02 \\
\hline 4 & $\mathrm{CHB}$ & C20 & 0.00 & 0.00 & 0.00 & 0.05 & 0.02 \\
\hline 5 & $\mathrm{CHC}$ & C5 & 0.00 & 0.00 & 0.00 & 0.05 & 0.02 \\
\hline 6 & $\mathrm{CHD}$ & C10 & 0.00 & 0.00 & 0.00 & 0.05 & 0.02 \\
\hline 7 & NA & N24 & -0.18 & -0.18 & -0.18 & -0.18 & -0.18 \\
\hline 8 & $\mathrm{C} 1 \mathrm{~A}$ & C16 & 0.12 & 0.12 & 0.06 & 0.17 & 0.14 \\
\hline 9 & $\mathrm{C} 2 \mathrm{~A}$ & C17 & -0.06 & -0.06 & -0.12 & -0.01 & -0.04 \\
\hline 10 & C3A & C18 & -0.06 & -0.06 & -0.12 & -0.01 & -0.04 \\
\hline 11 & C4A & C19 & 0.12 & 0.12 & 0.06 & 0.17 & 0.14 \\
\hline 12 & CMA & - & 0.00 & 0.00 & 0.00 & 0.00 & 0.00 \\
\hline 13 & CAA & - & 0.00 & 0.00 & 0.00 & 0.00 & 0.00 \\
\hline 14 & CBA & - & -0.10 & -0.10 & -0.10 & -0.10 & -0.10 \\
\hline 15 & CGA & - & 0.62 & 0.62 & 0.62 & 0.62 & 0.62 \\
\hline 16 & O1A & - & -0.76 & -0.76 & -0.76 & -0.76 & -0.76 \\
\hline 17 & $\mathrm{O} 2 \mathrm{~A}$ & - & -0.76 & -0.76 & -0.76 & -0.76 & -0.76 \\
\hline 18 & NB & N21 & -0.18 & -0.18 & -0.18 & -0.18 & -0.18 \\
\hline 19 & C1B & $\mathrm{C} 1$ & 0.12 & 0.12 & 0.06 & 0.17 & 0.14 \\
\hline 20 & $\mathrm{C} 2 \mathrm{~B}$ & $\mathrm{C} 2$ & -0.06 & -0.06 & -0.12 & -0.01 & -0.04 \\
\hline 21 & C3B & $\mathrm{C} 3$ & -0.06 & -0.06 & -0.12 & -0.01 & -0.04 \\
\hline 22 & C4B & C4 & 0.12 & 0.12 & 0.06 & 0.17 & 0.14 \\
\hline
\end{tabular}




\begin{tabular}{|c|c|c|c|c|c|c|c|}
\hline 23 & $\mathrm{CMB}$ & - & 0.00 & 0.00 & 0.00 & 0.00 & 0.00 \\
\hline 24 & $\mathrm{CAB}$ & - & 0.00 & 0.00 & 0.00 & 0.00 & 0.00 \\
\hline 25 & CBB & - & 0.00 & 0.00 & 0.00 & 0.00 & 0.00 \\
\hline 26 & $\mathrm{NC}$ & N22 & -0.18 & -0.18 & -0.18 & -0.18 & -0.18 \\
\hline 27 & $\mathrm{C} 1 \mathrm{C}$ & C6 & 0.12 & 0.12 & 0.06 & 0.17 & 0.14 \\
\hline 28 & $\mathrm{C} 2 \mathrm{C}$ & $\mathrm{C} 7$ & -0.06 & -0.06 & -0.12 & -0.01 & -0.04 \\
\hline 29 & C3C & C8 & -0.06 & -0.06 & -0.12 & -0.01 & -0.04 \\
\hline 30 & $\mathrm{C} 4 \mathrm{C}$ & $\mathrm{C9}$ & 0.12 & 0.12 & 0.06 & 0.17 & 0.14 \\
\hline 31 & $\mathrm{CMC}$ & - & 0.00 & 0.00 & 0.00 & 0.00 & 0.00 \\
\hline 32 & CAC & - & 0.00 & 0.00 & 0.00 & 0.00 & 0.00 \\
\hline 33 & CBC & - & 0.00 & 0.00 & 0.00 & 0.00 & 0.00 \\
\hline 34 & ND & N23 & -0.18 & -0.18 & -0.18 & -0.18 & -0.18 \\
\hline 35 & C1D & C11 & 0.12 & 0.12 & 0.06 & 0.17 & 0.14 \\
\hline 36 & C2D & C12 & -0.06 & -0.06 & -0.12 & -0.01 & -0.04 \\
\hline 37 & C3D & C13 & -0.06 & -0.06 & -0.12 & -0.01 & -0.04 \\
\hline 38 & C4D & C14 & 0.12 & 0.12 & 0.06 & 0.17 & 0.14 \\
\hline 39 & CMD & - & 0.00 & 0.00 & 0.00 & 0.00 & 0.00 \\
\hline 40 & CAD & - & 0.00 & 0.00 & 0.00 & 0.00 & 0.00 \\
\hline 41 & CBD & - & -0.10 & -0.10 & -0.10 & -0.10 & -0.10 \\
\hline 42 & CGD & - & 0.62 & 0.62 & 0.62 & 0.62 & 0.62 \\
\hline 43 & O1D & - & -0.76 & -0.76 & -0.76 & -0.76 & -0.76 \\
\hline 44 & O2D & - & -0.76 & -0.76 & -0.76 & -0.76 & -0.76 \\
\hline Total: & & & -1.00 & -1.00 & -1.00 & -1.00 & -1.00 \\
\hline
\end{tabular}

\footnotetext{
${ }^{\mathrm{a}}$ The ferric state has no 6:th Fe-ion coordination. The ferryl oxygen of co I is denoted OXO and that of co II is denoted $\mathrm{OXH}$ to indicate the possibility of a nearby proton.
} 
(3) Partial atomic charges assigned to indole substrates

Table S2

Gasteiger charges for the AutoDock ligands obtained with SYBYL 6.9.1

\begin{tabular}{|c|c|c|c|c|c|}
\hline \multirow[b]{2}{*}{ Atom } & \multicolumn{5}{|c|}{ Ligand charges (e u) } \\
\hline & MLT & SRT & SRT & FER & BHA \\
\hline & & (protonated) & (unprotonated) & & \\
\hline C1 & 0.094 & 0.073 & 0.073 & -0.033 & 0.034 \\
\hline $\mathrm{C} 2$ & 0.025 & 0.042 & 0.042 & 0.051 & 0.017 \\
\hline C3 & 0.015 & 0.003 & 0.003 & 0.102 & 0.001 \\
\hline C4 & 0.057 & 0.039 & 0.039 & 0.099 & 0.000 \\
\hline C5 & 0.019 & 0.026 & 0.026 & 0.040 & 0.001 \\
\hline C6 & 0.026 & 0.034 & 0.034 & 0.014 & 0.017 \\
\hline C7 & 0.068 & 0.076 & 0.076 & 0.018 & 0.275 \\
\hline C8 & -0.002 & -0.020 & -0.023 & 0.085 & - \\
\hline C9 & 0.052 & 0.088 & 0.052 & 0.198 & - \\
\hline C10 & 0.105 & 0.132 & 0.082 & 0.210 & - \\
\hline C11 & 0.231 & - & - & - & - \\
\hline C12 & 0.097 & - & - & - & - \\
\hline C13 & 0.181 & - & - & - & - \\
\hline H1 & 0.166 & 0.152 & 0.152 & 0.217 & 0.197 \\
\hline $\mathrm{H} 2$ & 0.163 & 0.217 & 0.217 & - & 0.244 \\
\hline H3 & - & 0.199 & 0.118 & - & - \\
\hline $\mathrm{H} 4$ & - & 0.199 & 0.118 & - & - \\
\hline H5 & - & 0.199 & - & - & - \\
\hline N1 & -0.352 & -0.320 & -0.320 & - & -0.233 \\
\hline N2 & -0.345 & 0.219 & -0.330 & - & - \\
\hline O1 & -0.328 & -0.360 & -0.360 & -0.645 & -0.265 \\
\hline $\mathrm{O} 2$ & -0.273 & - & - & -0.645 & -0.287 \\
\hline
\end{tabular}




\begin{tabular}{llllll} 
O3 & - & - & - & -0.353 & - \\
O4 & - & - & - & -0.358 & - \\
& & & & & \\
Total & $\mathbf{- 0 . 0 0 1}$ & $\mathbf{0 . 9 9 8}$ & $\mathbf{- 0 . 0 0 1}$ & $\mathbf{- 1 . 0 0 0}$ & $\mathbf{0 . 0 0 1}$ \\
$\mathbf{p K a}^{\mathbf{a}}$ & - & $\mathbf{9 . 8}$ & $\mathbf{4 . 6}$ & $\mathbf{8 . 8}$ \\
\hline a & & &
\end{tabular}




\section{Table S3}

Results of docking melatonin and serotonin into the active site of horseradish peroxidase with AUTODOCK.

\begin{tabular}{|c|c|c|c|c|c|c|c|}
\hline $\begin{array}{l}\text { HRP } \\
\text { ox. } \\
\text { state }^{a}\end{array}$ & $\begin{array}{l}\text { Conf. } \\
\text { mode } \\
\text { name }\end{array}$ & $\begin{array}{l}\text { Mode } \\
\text { strength } \\
(\%)\end{array}$ & $\begin{array}{l}\text { Mode } \\
\text { docking } \\
\text { energy } \\
\left(\mathrm{kcal} \mathrm{mol}^{-1}\right)\end{array}$ & $\begin{array}{l}\text { Mode } \\
\text { orien- } \\
\text { tation }^{c}\end{array}$ & $\begin{array}{l}\text { Mode } \\
\text { att. to } \\
\text { heme } \\
\text { plane }^{d}\end{array}$ & $\begin{array}{l}\text { Indole } \\
\text { stackin } \\
\text { g ring }\end{array}$ & $\begin{array}{l}\text { Min. dist. Figure } \\
\text { of indole showing } \\
\text { atom to mode in } \\
\text { centre of given } \\
\text { D-pyrrole. color } \\
(\AA)^{f}\end{array}$ \\
\hline
\end{tabular}

\begin{tabular}{|c|c|c|c|c|c|c|c|}
\hline \multicolumn{8}{|c|}{ Melatonin } \\
\hline \multirow[t]{3}{*}{$F-F$} & $\mathrm{HMB}$ & 15 & -10.75 & SC & 1 & 6.36 & 7A yellow \\
\hline & $\mathrm{HMC}$ & 35 & -9.99 & IS & 1 & 4.12 & $7 \mathrm{~A}$ red \\
\hline & HMC2 & 12 & -9.77 & IS & I & 4.45 & \\
\hline \multirow[t]{5}{*}{$1-1$} & $\mathrm{HMB}$ & 11 & -10.89 & $\mathrm{SC}$ & l & 6.49 & 4A,6B, 7A blue \\
\hline & $\mathrm{HMC}^{\mathrm{g}}$ & 19 & -9.43 & IS & l & 4.18 & 4A,7A green, \\
\hline & & & & & & & $6 \mathrm{~A}, \mathrm{~S} 1 \mathrm{~A}$ blue \\
\hline & $\mathrm{HMC}^{\mathrm{g}}$ & 26 & -9.33 & IS & l & 4.16 & S1A,red \\
\hline & HMC4 & 13 & -9.33 & IS & I & 4.07 & S1A,green \\
\hline \multirow[t]{4}{*}{$2-2$} & $\mathrm{HMB}$ & 7 & -10.98 & $\mathrm{SC}$ & l & 6.24 & \\
\hline & $\mathrm{HMC}$ & 10 & -9.50 & IS & I & 4.20 & S1B, blue \\
\hline & HMC2 & 40 & -9.48 & IS & I & 4.62 & S1B,red \\
\hline & HMC3 & 8 & -9.53 & IS & I & 4.22 & S1B,yellow \\
\hline \multirow[t]{4}{*}{$F-1$} & HMA2 & 8 & -10.83 & IS & I & 4.39 & \\
\hline & HMB & 9 & -10.77 & SC & I & 6.33 & \\
\hline & $\mathrm{HMC}$ & 40 & -10.09 & IS & I & 4.20 & S2A, blue \\
\hline & HMC2 & 16 & -9.85 & IS & I & 4.46 & S2A, red \\
\hline \multirow[t]{4}{*}{$F-2$} & $\mathrm{HMB}$ & 7 & -10.72 & $\mathrm{SC}$ & I & 6.34 & \\
\hline & $\mathrm{HMC}$ & 39 & -10.09 & IS & I & 4.15 & S2B, blue \\
\hline & HMC2 & 12 & -9.85 & IS & I & 4.49 & S2B, red \\
\hline & HMC3 & 9 & -9.74 & IS & I & 4.48 & S2B, yellow \\
\hline
\end{tabular}

Protonated Serotonin

\begin{tabular}{|c|c|c|c|c|c|c|c|}
\hline$F-F$ & HSA & 83 & -9.56 & IS & 1 & 4.30 & $7 \mathrm{~B}$, red \\
\hline $1-1$ & HSA & 64 & -9.46 & IS & I & 4.22 & 4B, 7B, blue \\
\hline
\end{tabular}


$\begin{array}{lll}\text { HSC2 } & 32 \quad-8.79\end{array}$

\begin{tabular}{|c|c|c|c|c|c|}
\hline \multirow[t]{2}{*}{2} & HSA & 75 & -9.62 & IS & 1 \\
\hline & HSC & 23 & -8.87 & $\mathrm{SC}$ & 1 \\
\hline
\end{tabular}

\begin{tabular}{|c|c|c|c|c|c|c|c|}
\hline \multicolumn{8}{|c|}{ Unprotonated Serotonin } \\
\hline \multirow[t]{3}{*}{$F-F$} & HSA & 46 & -8.75 & IS & l & 4.18 & \\
\hline & HSC & 28 & -8.86 & $\mathrm{SC}$ & I & 4.06 & \\
\hline & HSD & 13 & -8.73 & 1 & - & 4.69 & \\
\hline \multirow[t]{3}{*}{$1-1$} & HSA & 37 & -8.51 & IS & l & 4.20 & $6 \mathrm{~A}$, green \\
\hline & HSC & 38 & -8.62 & SC & l & 4.75 & $6 \mathrm{~B}$, orange \\
\hline & HSC3 & 23 & -8.70 & SC & l & 5.20 & \\
\hline \multirow[t]{3}{*}{$2-2$} & HSA & 42 & -8.66 & IS & l & 4.20 & \\
\hline & HSC & 43 & -8.72 & $\mathrm{SC}$ & l & 4.54 & \\
\hline & HSC3 & 13 & -8.72 & SC & l & 5.23 & \\
\hline \multicolumn{8}{|c|}{$\begin{array}{l}\text { a HRP oxidation state is denoted with the conformational part first and the chemical/electrostatic part second (F - } \\
\text { ferric, } 1 \text { - compound I and } 2 \text { - compound 2). }\end{array}$} \\
\hline \multicolumn{8}{|c|}{$\begin{array}{l}\text { b Modes are designated by three letter names (plus a numeral if two or more modes are similar) and defined by } \\
\text { clustering with a } 1.0 \AA \text { RMSD tolerance unless otherwise specified. }\end{array}$} \\
\hline \multicolumn{8}{|c|}{$\begin{array}{l}\text { c Part of the ligand that is presented toward the heme Fe-ion (IS - Indole substituent, SC - Sidechain, I - Indole } \\
\text { aromatic rings). }\end{array}$} \\
\hline \multicolumn{8}{|c|}{$\begin{array}{l}\text { Descriptor of the indole aromatic ring plane as either having less than a } 5^{\circ} \text { angle from the heme plane (parallel, -) } \\
\text { or more than } 5^{\circ} \text { (non parallel, } / \text { ). }\end{array}$} \\
\hline \multicolumn{8}{|c|}{$\begin{array}{l}\text { The particular ligand aromatic ring that is in a good position to make aromatic stacking with the D-pyrrole of the } \\
\text { heme ( } 5 \text { - pyrrole part of indole ring, } 6 \text { - phenyl part of indole ring, } 5 \text { \& } 6 \text { - both, . - none). }\end{array}$} \\
\hline \multicolumn{8}{|c|}{ stance from the centre of the heme D-pyrrole ring to the clo } \\
\hline \multicolumn{8}{|c|}{$\begin{array}{l}\text { These submodes were obtained from a clustering using a } 0.6 \AA \text { RMSD tolerance. In the original } 1.0 \AA \text { clustering, the } \\
\text { HMC mode alone covers these modes with a mode strength of } 45 \% \text {. }\end{array}$} \\
\hline
\end{tabular}




\section{Table S4}

Results of docking melatonin and serotonin into the active site of myeloperoxidase with AUTODOCK.

\begin{tabular}{|c|c|c|c|c|c|c|c|}
\hline $\begin{array}{l}\text { MPO } \\
\text { ox. } \\
\text { state }^{\text {a }}\end{array}$ & $\begin{array}{l}\text { Conf. } \\
\text { mode } \\
\text { name }\end{array}$ & $\begin{array}{l}\text { Mode } \\
\text { strength } \\
(\%)\end{array}$ & $\begin{array}{l}\text { Mode } \\
\text { docking } \\
\text { energy } \\
\left(\mathrm{kcal} \mathrm{mol}^{-1}\right)\end{array}$ & $\begin{array}{l}\text { Mode } \\
\text { orien- } \\
\text { tation }^{c}\end{array}$ & $\begin{array}{l}\text { Mode } \\
\text { att. to } \\
\text { heme } \\
\text { plane }\end{array}$ & $\begin{array}{l}\text { Indole } \\
\text { stackin } \\
\text { g ring }\end{array}$ & $\begin{array}{ll}\text { Min. dist. of } & \text { Figure } \\
\text { indole atom } & \text { showing } \\
\text { to centre of } & \text { mode in } \\
\text { D-pyrrole. } & \text { given color } \\
(\AA)^{f} & \end{array}$ \\
\hline
\end{tabular}

Melatonin

\begin{tabular}{|c|c|c|c|c|c|c|c|c|}
\hline \multirow[t]{4}{*}{$F-F$} & MMA & 8 & -12.18 & IS & - & 6 & 3.54 & $8 \mathrm{~A}$, green \\
\hline & MMB & 7 & -10.84 & I & - & 5 & 3.47 & $8 \mathrm{~A}$, red \\
\hline & MMC & 38 & -10.41 & IS & - & 6 & 3.51 & \\
\hline & MME & 11 & -9.81 & I & - & 5 & 3.51 & \\
\hline \multirow[t]{3}{*}{ F - 1} & MMB & 9 & -11.03 & I & - & 5 & 3.30 & $5 \mathrm{~A}, 8 \mathrm{~A}$, blue, $6 \mathrm{~B}$ red \\
\hline & MMC & 41 & -10.55 & IS & - & 6 & 3.53 & $5 A, 6 A$, red \\
\hline & MME & 26 & -10.18 & I & - & 5 & 3.51 & $5 \mathrm{~A}, 6 \mathrm{~B}$, green \\
\hline \multirow[t]{3}{*}{$F-2$} & MMB & 9 & -11.07 & I & - & 5 & 3.42 & \\
\hline & MMC & 43 & -10.56 & IS & - & 6 & 3.51 & \\
\hline & MME & 20 & -10.17 & I & - & 5 & 3.54 & \\
\hline
\end{tabular}

Protonated serotonin

$\begin{array}{lllllllll}\text { F - F } & \text { MSA2 } & 48 & -10.26 & \text { IS } & - & 6 & 3.40 & 8 \mathrm{~B} \text {, yellow } \\ & \text { MSC2 } & 31 & -9.69 & \text { I } & - & 5 \& 6 & 3.46 & 8 \mathrm{~B}, \text { green } \\ \text { F - 1 } & \text { MSB } & 36 & -10.11 & \text { IS } & - & 6 & 3.44 & 5 \mathrm{~B}, 8 \mathrm{~B} \text {, blue } \\ & \text { MSC2 } & 33 & -9.77 & \text { I } & - & 5 \& 6 & 3.45 & 5 \mathrm{~B}, 8 \mathrm{~B}, \text { orange } \\ \text { F - 2 } & \text { MSB } & 31 & -10.15 & \text { IS } & - & 6 & 3.45 & \\ & \text { MSC2 } & 33 & -9.79 & \text { I } & - & 5 \& 6 & 3.44 & \end{array}$

Unprotonated serotonin

$\begin{array}{llllllll}F-F & \text { MSA } & 44 & -9.57 & \text { IS } & - & 6 & 3.55 \\ & \text { MSA2 } & 17 & -9.39 & \text { IS } & - & 6 & 3.40\end{array}$



MSC
24
$-8.86$
$1 \quad-$
$5 \& 6 \quad 3.48$

F - 1

$\begin{array}{rllllllll} & \text { MSB } & 34 & -9.30 & \text { IS } & - & 6 & 3.44 & 6 \mathrm{~A} \text {, orange } \\ & \text { MSC } & 38 & -8.99 & \text { I } & - & 5 \& 6 & 3.49 & 6 \mathrm{~B}, \text { yellow } \\ \mathrm{F}-2 & \text { MSB } & 43 & -9.28 & \text { IS } & - & 6 & 3.44 & \\ & \text { MSC } & 27 & -9.00 & \text { I } & - & 5 \& 6 & 3.49 & \end{array}$

MPO oxidation state is denoted with the conformational part first and the chemical/electrostatic part second (F - ferric, 1 a compound I and 2 - compound 2).

Modes are designated by three letter names (plus a numeral if two or more modes are similar) with a $1.0 \AA$ RMSD

b tolerance unless otherwise specified.

c Part of the ligand that is presented toward the heme Fe-ion (IS - Indole substituent, SC - Sidechain, I - Indole aromatic rings).

Descriptor of the indole aromatic ring plane as either having less than a $5^{\circ}$ angle from the heme plane (parallel, -) or more than $5^{\circ}$ (non parallel, /).

e

The particular ligand aromatic ring that is in a good position to make aromatic stacking with the D-pyrrole ring of the heme (5 $f$ - pyrrole part of indole ring, 6 - phenyl part of indole ring, $5 \& 6$ - both, . - none).

The distance from the centre of the heme D-pyrrole ring to the closest indole atom of the mode. 

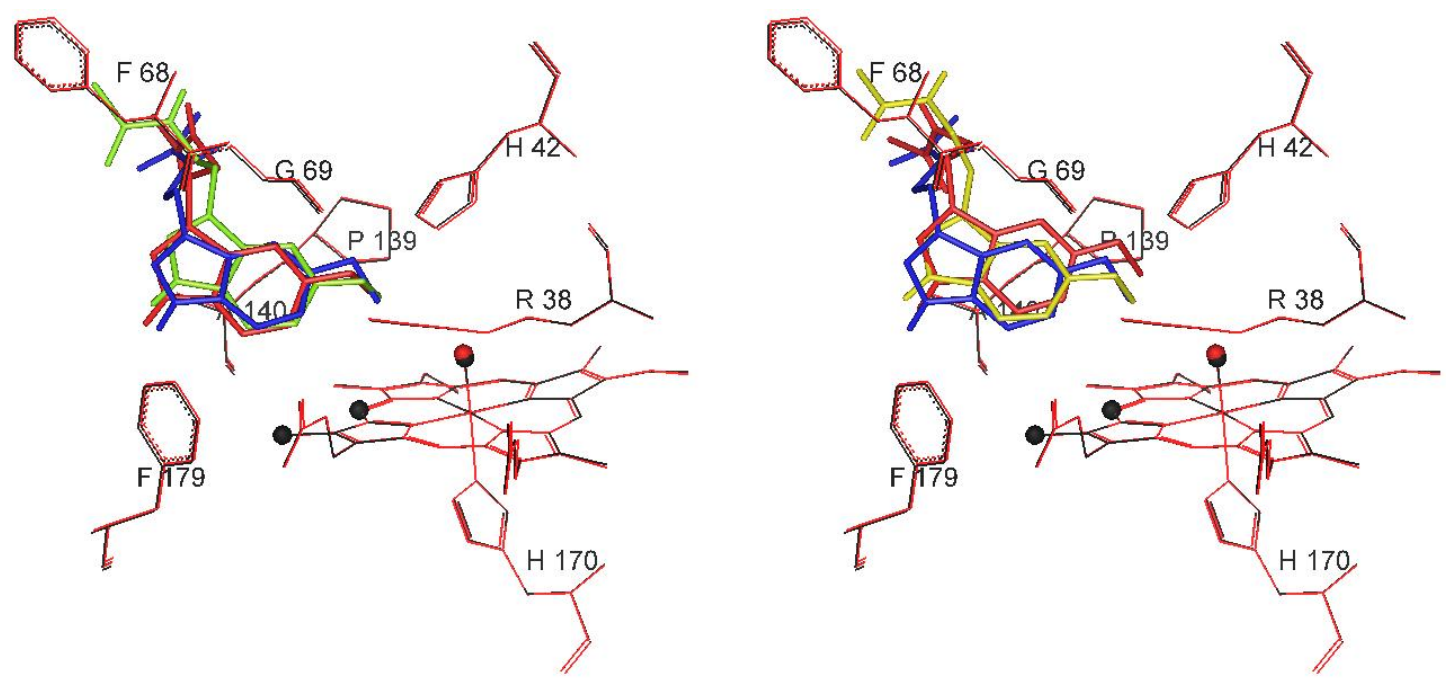

A

B

Figure S1. Superposition of HRP co I (black) and co II (red) active sites showing IS docking modes for MLT. The C18 methyl, C20 and the ferryl oxygen are represented as balls in the color of the respective HRP state. (A) co I: HMC (blue), HMC2 (red) and HMC4 (green) modes. (B) co II: HMC (blue), HMC2 (red) and HMC3 (yellow) modes. 


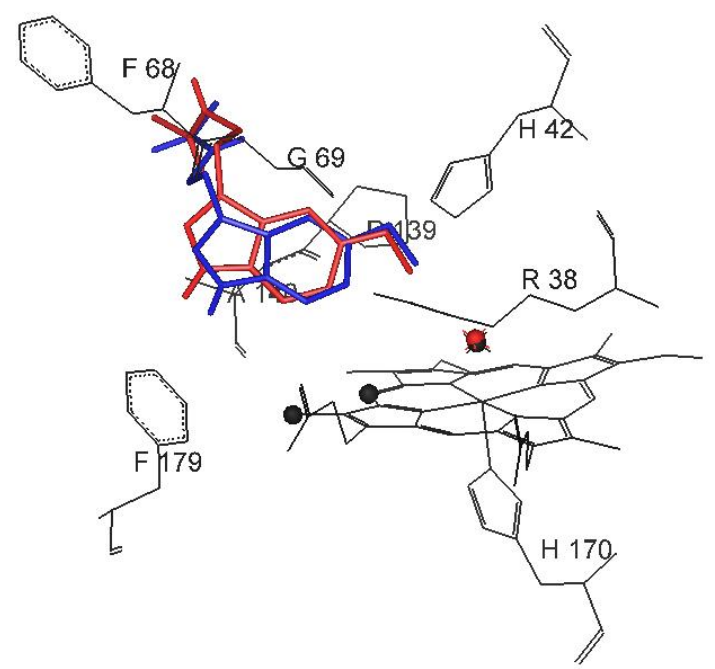

A

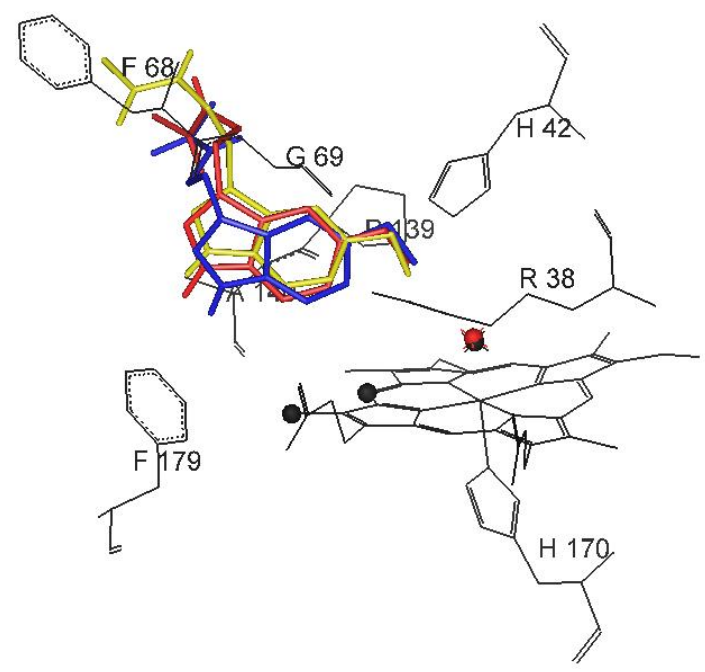

B

Figure S2. Dominant IS docking modes of MLT to the ferric state HRP with the ferryl oxygens of co I (black ball) and co II (red ball) added to emulate co I and co II without other structural changes. The C18 methyl and C20 are represented as black balls. (A) co I: HMC (blue) and HMC2 (red) modes. (B) co II: HMC (blue), HMC2 (red) and HMC3 (yellow) modes. 